\title{
Will royal patronage improve perceptions of mental illness?
}

\author{
Emeritus Professor Alan Glasper, from the University of Southampton, discusses the stigma still suffered by \\ people with mental health disorders and whether a recently launched campaign can help challenge it
}

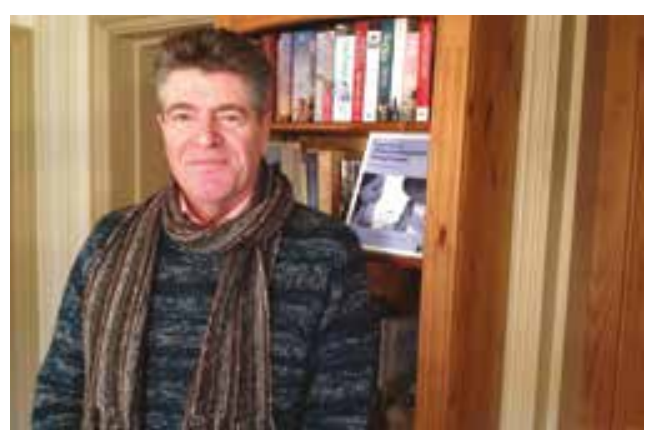

W ith news of an initiative for people with mental health problems launched by the Duke and Duchess of

Cambridge and Prince Harry, it is timely to review perceptions of mental health in society. The quest by the royals is to de-stigmatise mental illness and to bring it into line with physical health problems and therefore public acceptability (Booth, 2017).

The Duke and his brother Harry have endeavoured to raise the public profile of mental health for some time and have themselves publicly discussed the impact of their mother Princess Diana's death in August 1997 on their own mental health. Many will recall seeing the two young royals as they walked stoically alongside their mother's funeral cortege from St James's Palace to Westminster Abbey, and some will have pondered on the effect it might have on them. Prince Harry has now revealed that he accessed counselling support in his late $20 \mathrm{~s}$ to help him deal with the residual aftermath of his mother's premature death when he was only 12 years of age, and admitted that he had come close to a complete mental health breakdown (Kennedy, 2017).

Prince Harry has often been perceived by the press as the perpetual party-loving prince, and this admission that he had ignored his own mental illness symptoms for a number of years before eventually seeking help from a counsellor has made a major contribution to addressing the stigma attached to mental health issues. The royals have launched the 'Heads Together' campaign (http://tinyurl.com/n5ypkd8), which aspires to reduce the stigma surrounding mental health issues, and to encourage people to speak more openly about their emotional problems. The campaign aims to change the national conversation on mental wellbeing and is part of a partnership involving a range of well-known charities with many years of experience in tackling stigma, raising awareness, and providing vital help for people with mental health challenges.

The Heads Together campaign is part of a raft of charitable causes that are supported by the Duke and Duchess of Cambridge and Prince Harry through The Royal Foundation, their primary charitable vehicle. This includes, among others, the 'Endeavour Fund', which supports the recovery of wounded, injured and sick servicemen and women (http:// tinyurl.com/lt6xe4l).

\section{Mental illness and stigma}

Nursing academics such as Carpenter (2010) and Nolan (2000) have discussed the rich history of mental health nursing. Although derogatory words such as 'lunatic' or 'maniac' are no longer used to describe people with mental health problems, the stigma that lies beneath these terms continues to prevail among many in society, where mental illness is perceived to be somehow a weakness or the sign of a flawed personality. The treatment of men emotionally traumatised in battle is a case in point. For example, during the First World War, 306 men were executed for cowardice when in fact many were suffering shell shock, recognised today as post-traumatic stress disorder (Fenton, 2006).

Although attitudes towards the treatment of people with mental health problems has changed over time, with the lunatic asylums and mad houses offering more than just custodial management, it was another royal, George III, who, in the latter part of the 18th century, changed the way in which those with mental health issues were perceived. King George suffered from periodic bouts of mental ill-health probably caused by porphyria, an inherited metabolic disorder. His illness was made famous by the film The Madness of King George in 1994.

Baly (1993) observed that, being the king, it was impossible for lesser mortals to adhere to a commonly held notion at that time that mental ill health was caused by the committing of sin. Thus the king was responsible for a more tolerant approach to those with mental health problems.

However, portrayals of those with mental illnesses in literature remained disparaging and the stigma persisted. For example, in Charlotte Brontë's novel Jane Eyre, first published in 1847, the hero Edward Rochester's wife is depicted as a violent madwoman locked in the attic who escapes to burn down their home, Thornfield Hall. Also of interest is Brontë's depiction of nurse Grace Poole, hired by Rochester to look after his mentally ill wife, who she portrays simply as an often drunk and careless custodian.

\section{Campaign aims}

The primary mission of the royal initiative is to encourage people affected by mental health issues to speak more openly about their difficulties and also to get people to talk more about mental health generally. Mental health problems can affect anyone in society and it is the stigma and the perceived and actual discrimination that prevents people being more open about their emotional experiences and seeking appropriate help and not relying on self-medication through drugs and alcohol.

Men are traditionally reluctant to seek help and yet talking about mental health has been shown to strengthen friendships, aid 
recovery, break down stereotypes and reduce the taboo and stigma associated with mental illness (O'Brien et al, 2005). Worryingly, it is young men from minority ethnic groups who tend to be the most reluctant to seeking appropriate help (Rickwood et al, 2007).

The Duke of Cambridge has emphasised the UK's high rates of male suicide, which reflect the consequences of untreated or poorly managed mental health disorders. In particular, young men who leave the UK armed forces have an increased risk of suicide (Kapur et al, 2009). The three royals are fully cognisant that unresolved mental health problems are part of the cause of some of the country's greatest social challenges and their quest is to give mental health the same status as physical health. The princes' experiences in the armed forces has shown them that many people feel apprehensive about revealing that they are struggling to cope with their emotional problems. Fear of the prejudice and value judgements of others can stop some people from getting the help and support they need, which often damages family cohesion and can end in untimely and needless deaths.

Heads Together will work with other charities and will give fresh impetus to the goal of eradicating the stigma that surrounds mental health so that the prejudice and fear experienced by mental health sufferers does not stop people getting the help and care they need. The charities currently working with Heads Together are:

- Best Beginnings, which aims to support parents in giving their children the best start in life (http://tinyurl.com/mp47t7y)

- CALM, the Campaign Against Living Miserably, a charity dedicated to preventing male suicide (http://tinyurl.com/motx $5 \mathrm{~d} 2$ )

- Contact-Rethink Mental Illness, whose goal is a better life for everyone affected by mental illness (http://tinyurl.com/ kgtp7hd)

- Place2Be, which provides emotional and therapeutic services to children in primary and secondary schools, helping them to cope with wide-ranging and often complex social issues including bullying, bereavement, domestic violence, family breakdown, neglect and trauma (http:// tinyurl.com/hmbxl95)

- The Mix, which supports young people to help them cope with various issues including mental health and drugs (http:// tinyurl.com/lvpfmfu).

\section{Discussion}

The positive media coverage of the royal campaign is commendable, but within the same period it was revealed, by the GPs' journal Pulse, that mental health trusts in England are still having their budgets cut, despite government assurances that they would be funded on a par with physical healthcare (Wickware, 2017). Using data obtained via freedom of information requests from 127 clinical commissioning groups (CCGs) in England, Pulse suggests that mental health spending is being cut by E4.5 million in five English regions during 2017, with the largest cut of $\mathcal{\delta} 1.9$ million or $3.6 \%$ being made in Walsall, in the West Midlands. It also suggested that many children and young people with mental health problems are being denied treatment after being referred by their GP.The article cites data from 15 mental health trusts, which revealed that $60 \%$ of GP referrals to child and adolescent mental health services (CAMHS) resulted in no treatment being offered, with 33\% not being fully assessed (Wickware, 2017).

Data from The King's Fund supports these claims, and show that in 2013-14 and 2014-15, approximately $40 \%$ of mental health trusts continued to experience annual reductions to their budgets. This is despite assurances from NHS England in 2014 that by 2020 all CCGs would increase their mental health spending in real terms (Gilburt,2017).

\section{Conclusion}

The Heads Together initiative has undoubtedly led to positive media coverage of the stigma attached to people who experience mental health problems. Given such media attention, it is to be hoped that their efforts will be rewarded after the general election with the new government committing to providing more funding for mental health care. BJN

\section{KEY POINTS}

- The Duke and Duchess of Cambridge and Prince Harry are endeavouring to raise the public profile of mental health through their 'Heads Together' campaign

- The campaign aspires to reduce the stigma surrounding mental health issues, and to encourage people to speak more openly about their emotional problems

- Heads Together will work with other charities and will give fresh impetus to the goal of eradicating the stigma that surrounds mental health

- Mental health trusts in England are still having their budgets cut, despite government assurances that they would be funded on a par with physical healthcare

Baly MF (1993) Nursing and Social Change. 3rd edn. Taylor and Francis, Abingdon

Booth R (2017) Royals launch campaign to get Britons talking about mental health. The Guardian 29 March. http://tinyurl.com/kvefnnh (accessed 11 May 2017)

Brontë C (2006) Jane Eyre. Penguin Books, London

Carpenter DT (2010) Above all a patient should never be terrified: an examination of mental health care and treatment in Hampshire 1845-1914. PhD thesis. University of Portsmouth. http://tinyurl.com/ks36zwk (accessed 11 May 2017)

Fenton B (2006) Pardoned: the 306 soldiers shot at dawn for 'cowardice'. The Telegraph 16 August. http://tinyurl. $\mathrm{com} / \mathrm{kz} 4 \mathrm{~h} 58 \mathrm{n}$ (accessed 11 May 2017)

Gilburt H (2017) Trust finances raise concerns about the future of the Mental Health Taskforce recommendations. The King's Fund. 14 October. http://tinyurl.com/m8ac39v (accessed 11 May 2017)

Kapur N, While D, Blatchley N, Bray I, Harrison K (2009) Suicide after leaving the UK armed forces - a cohort study. PLoS Med 6(3): e26. https://dx.doi.org/10.1371/ journal.pmed.1000026

Kennedy M (2017) Prince Harry grief revelations draw praise from mental health experts. The Guardian 17 April. http://tinyurl.com/14qzp4t (accessed 11 May 2017)

Nolan P (2000) A History of Mental Health Nursing. Blackwell, Oxford

O'Brien R, Hunt K, Hart G (2005) 'It's caveman stuff, but that is to a certain extent how guys still operate' men's accounts of masculinity and help seeking. Soc Sci Med 61(3): 503-16. https://doi.org/10.1016/j. socscimed.2004.12.008

Rickwood DJ, Deane FP, Wilson CJ (2007) When and how do young people seek professional help for mental health problems? Med J Aust 187(7 Suppl): S35-39

Wickware C (2017) CCGs cutting spending on mental health despite NHS pledge. Pulse 17 April. http:// tinyurl.com/mdxsqpd (accessed 11 May 2017)

\section{Have an idea for BJN?}

\section{4 bjn@markallengroup.com @ @}

